\title{
GCU
}

Glasgow Caledonian

University

University for the Common Good

\section{An interpretative phenomenological analysis of the experience of living with colorectal cancer as a chronic illness}

McGeechan, Grant J.; McPherson, Kerri E.; Roberts, Karen

Published in:

Journal of Clinical Nursing

DOI:

10.1111/jocn.14509

Publication date:

2018

Document Version

Author accepted manuscript

Link to publication in ResearchOnline

Citation for published version (Harvard):

McGeechan, GJ, McPherson, KE \& Roberts, K 2018, 'An interpretative phenomenological analysis of the

experience of living with colorectal cancer as a chronic illness', Journal of Clinical Nursing, vol. 27, no. 15-16, pp. 3148-3156. https://doi.org/10.1111/jocn.14509

\section{General rights}

Copyright and moral rights for the publications made accessible in the public portal are retained by the authors and/or other copyright owners and it is a condition of accessing publications that users recognise and abide by the legal requirements associated with these rights.

Take down policy

If you believe that this document breaches copyright please view our takedown policy at https://edshare.gcu.ac.uk/id/eprint/5179 for details

of how to contact us. 
An interpretative phenomenological analysis of the experience of living with colorectal cancer as a chronic illness.

\section{Running head - Living with colorectal cancer as a chronic illness}

Grant J. McGeechan, $\mathrm{PhD},{ }^{(1) *}$, Kerri E. McPherson, $\mathrm{PhD}^{(2)}$, Karen Roberts, $\mathrm{PhD}^{(1)}$

${ }^{1}$ School of Health and Life Sciences, Northumbria University, Newcastle upon Tyne, NE7 7XA

${ }^{2}$ School of Health and Life Sciences, Glasgow Caledonian University, Glasgow G4 0BA

Correspondence to Dr Grant J. McGeechan, School of Social Sciences, Humanities, and Law, Clarendon Building, Teesside University, Borough Road, Middlesbrough, TS1 3BXA; g.mcgeechan@tees.ac.uk 


\begin{abstract}
Aims and objectives

The main aim of this study was to explore the lived experiences of patients living with cancer as a chronic illness.

Background
\end{abstract}

Due to recent advances in detection and treatment, cancer is now regarded as a chronic illness. However, living with cancer as a chronic illness can lead to a number of physical and psychosocial consequences all of which can lead to uncertainty over how patients view and plan for their future.

\title{
Design
}

A longitudinal qualitative study.

\section{Methods}

Individuals attending oncology follow-up clinics with their clinical nurse specialist at a hospital in the North East of England were invited to participate in two semi-structured interviews over a 6-month period. A total of six individuals consented to participate, of whom two were women. One participant could not be contacted for the second interview, resulting in 11 interviews. Interviews were audio recorded, transcribed verbatim, pseudonymised and analysed using interpretative phenomenological analysis.

Results

Two superordinate themes emerged from the analysis; physical and psychological consequences of cancer; and adapting to life after treatment. 


\section{Conclusion}

The experience of future disorientation was common amongst participants however this was impacted on by a number of factors such as functional impairment, and fear of recurrence. Furthermore, future disorientation does not appear to be stable and may ease as patients begin to adjust to the uncertainty of living with colorectal cancer as a chronic illness.

What is known about the topic?

- Living with and beyond colorectal cancer can leave patients susceptible to a number of physiological and psychological outcomes.

- Living with and beyond cancer can leave patients feeling unable to look ahead and plan for their future following treatment.

- The NHS has surmised that supportive care following cancer falls short, and more can be done to help the transition into survivorship.

What does this paper contribute to the wider global clinical community?

- Living with colorectal cancer as a chronic illness can lead to feelings of future disorientation, something previously only reported in women living with and beyond gynaecological cancer.

- Future disorientation is not a table construct for patients living with cancer as a chronic illness with some participants reporting it peaking at certain times such as the anniversary of their diagnosis, or immediately prior to follow-up appointments. 
Keywords: cancer; chronic illness; qualitative study; phenomenology. 


\section{Introduction}

Each year over 14 million new cases of cancer are diagnosed worldwide (Cancer Research UK, 2018a), with 359,960 new cases diagnosed in the United Kingdom (UK) alone. By 2040, the number of new cancer diagnoses is expected to increase by over $70 \%$ worldwide, with the majority of these new cases occurring in middle to low income countries (WHO, 2018). The growing number of cancer incidences combined with recent advances in treatment and detection mean that more and more people are living with and beyond cancer. In the United Kingdom, $50 \%$ of adults diagnosed with cancer can expect to survive for 10 years or more (Cancer Research UK, 2018b). Whilst the impact of cancer will depend on the type of tumour and the stage of disease when one is diagnosed, it is clear that those living with and beyond any cancer must learn to cope with the physical and psychological consequences of both the disease itself and its treatment (Drageset, Lindstrøm, \& Underlid, 2016). It is common for patients to experience a number of late side effects following treatment including fear of cancer recurrence (Gahzzali, Cadwallader, Humphris, Ozakinici, \& Roger, 2012; Handschel, Naujoks, Kubler, \& Kruskemper, 2012; Herschbach \& Dinkel, 2014; Lebel et al., 2016), and physical and mental functional impairment (Kiserud, Dahl, Loge, \& Frossa, 2014; Pélissier, Fontana, \& Chauvin, 2014; Rodriguez, Hawkins, Berkowitz, \& Li, 2015). These difficulties can permeate all aspects of a patient's life as they move into survivorship which can impact on the techniques, and adaptive strategies they use to manage their condition, and they can affect how they plan for their future lives post treatment (Maughan \& Clarke, 2001; Roberts \& Clarke, 2009; Appleton, Goodlad, Irvine, Poole \& Wall, 2013).

Colorectal cancer is one of the four most common cancers to occur worldwide, and along with prostate cancer, female breast cancer and lung cancer, it accounts for $40 \%$ of all cancer 
diagnoses (Cancer Research UK, 2018a). Within the UK, colorectal cancer is the fourth most common cancer affecting both men and women, with approximately 35,000 people diagnosed each year in England alone (Office for National Statistics, 2017a). Around 58\% of those diagnosed with colorectal cancer can expect to survive for five years or more (Office for National Statistics, 2017b), however often those living with and beyond colorectal cancer must learn to live with significant physical and psychological consequences (Horikoshi \& Futawatari, 2017).

Previous research into the experience of living with and beyond colorectal cancer has highlighted the need to focus on the long-term management of the illness (Sahay, Gray \& Fitch, 2000). Despite this, patients may still be dissatisfied with the level of supportive care, and treatment information they receive following diagnosis (Brown, Greenfield \& Thompson, 2016; Ho et al, 2016). Indeed, the NHS commissioning board recently reported that cancer care falls short in the UK and more can be done to support patients following treatment (Independent Cancer Taskforce, 2015). Therefore, it is important that studies highlight the psychosocial consequences of living with cancer as a chronic illness so that appropriate support can be offered in the future.

Given the recent advances in survival rates for cancer, the World Health Organisation defines cancer as a chronic illness (Jiwa et al., 2008). However, it can be argued that cancer is unique in relation to other chronic illnesses as it is typically characterised by an acute phase of illness followed by long term complications in relation to treatment (Courneya, Mackey, \& Jones, 2000).

A number of theories have been proposed which aim to explain how individuals adapt to chronic illness such as biographical disruption (Bury, 1982) and loss of self (Charmaz, 1983). 


\section{Biographical disruption}

Biographical disruption has been used extensively in research looking at adaptation to chronic illness (Trusson, Pilnick, \& Roy, 2016) and relates to the disruption caused to one's everyday life following illness and the impact it can have on self-concept and hopes for the future (Bell, 2016).

Loss of Self

Loss of self is often posited in relation to chronic illness and relates to an erosion of self-identity stemming from restrictions in function related to the illness (Balfe et al., 2016).

\section{Future Disorientation}

However, these theories do not account for factors such as fear of recurrence which can have serious implications for post-treatment adjustment (Costanzo et al., 2007). In contrast, future disorientation explores how patients adapt to cancer as a chronic illness and is defined by Maughan and Clarke as a response to the chaos that emerges out of a cancer diagnosis and a realisation that patients are living with an uncertain future (Maughan \& Clarke, 2001). While similar to biographical disruption and loss of self, future disorientation introduces the idea that fear of recurrence and other specific consequences of cancer, such as infertility, have the ability to disrupt patient's views of the future. Previous studies of future disorientation have explored fear of recurrence, psychological, social, and infertility in women following treatment for gynaecological cancer (Maughan \& Clarke, 2001; Roberts \& Clarke, 2009) and breast cancer (Breaden, 1997). Given that infertility following treatment for colorectal cancer in men is a real possibility there is therefore a lack of research into future disorientation in men living with cancer as a chronic illness. Furthermore, previous research into future disorientation tends to be 
cross-sectional, which limits our understanding of the ways in which future disorientation manifests across time.

\section{Objectives}

The aim of this study was to qualitatively explore the psychosocial and physical consequences of living with colorectal cancer as a chronic illness and how this changes survivor's views and plans for their future, over time.

\section{Methodological Approach}

A qualitative design was used for this study with data collected through one-to-one interviews. Initial interviews were carried out between December 2011 and October 2012 with follow-up interviews taking place between and July 2012 and February 2013. All interviews took place in a private meeting room within a hospital, or at the participant's home depending on which they preferred. Interviews lasted for between 18 and 120 minutes, were transcribed verbatim and analysed using interpretative phenomenological analysis (IPA). Pseudonyms were utilised to protect participants identity. This study formed part of a $\mathrm{PhD}$ project looking at developing a conceptual framework of the experience of future disorientation in adults living with and beyond cancer.

\section{Participants}

Participants were recruited from oncology follow up clinics within a hospital in the North East of England. Clinical nurse specialists in oncology acted as gatekeepers for this study and they identified potential patients, provided them with invitation letters, and information sheets which explained the study in detail. The gatekeeper then passed the contact details of anyone who expressed an interest in participation on to the researcher. Gatekeepers did not record how many 
participants declined participation in the study therefore the uptake rate for the study is not known. Prior to each interview individuals were reminded that participation was voluntary, that they had the right to withdraw from the interview at any time, and that all information would be treated as confidential. However, they were informed that if they disclosed anything which suggested risk of harm to themselves or others, or if they became visibly distressed during then interview then the interview would be terminated and their clinical nurse specialist would be informed in the first instance.

In keeping with principles of IPA a small, homogenous sample was recruited for this study. IPA studies typically recruit samples of between six and 12 participants in order for a detailed description of each individual's experience to emerge (Smith, Flowers, \& and Larkin, 2009). Whilst ideally a purposive sample would have been recruited for this study, we were limited to those who expressed an interest in taking part. As only six participants expressed an interest in taking part in an interview a convenience sampling technique was used for this study. Participants had to be over 18 years of age, finished primary treatment for colorectal cancer and able to provide informed written consent. All participants described themselves as WhiteBritish, four were men and two were women, and all were between the ages of 44 and 72 years old $(\mathrm{M}=59.8)$. Patient characteristics can be seen in Table 1 below.

\section{Insert Table 1 here}

\section{Data Collection}

Each individual was interviewed on two occasions by the lead researcher (GM), six-months apart in order to capture the experience of future disorientation over time. The use of multiple 
interviews in IPA research can facilitate more in-depth consideration of a patient's experience than would be possible with a single interview (Maguire, Stoddart, Flowers, \& Larkin, 2014). One individual could not be contacted at follow up, this resulted in 11 interviews being conducted. Prior to the second interview the gatekeeper was contacted to assess whether or not it would be appropriate to contact participants for the second interview.

Semi-structured interviews were conducted with participants, with the interview schedule consisting of questions designed to prompt discussion about patients' experiences since being diagnosed with colorectal cancer. Participants were first asked to talk about their cancer journey from diagnosis to where they are today. The participants' experience of cancer was explored fully within the interviews, any mention of how their perception of the future may have changed since diagnosis was explored in more detail. The second interview followed almost the same format as the first interview with only the first question changing to 'Can you tell me about what has been happening in your life over the last six months?' All interviews were audio recorded and transcribed verbatim.

\section{Analysis}

All interviews were analysed using IPA, an idiographic methodology which focuses on the lived experience of individuals and aims to build a picture of what an experience is like by analysing the similarities and differences at an individual level before extrapolating them to the group to gain an overall understanding of the experience (Smith et al., 2009). The IPA analysis process involves immersing oneself in the data through repeated readings and the reviewing of the coding process before a final group of themes is produced for each transcript. Given the 
idiographic approach, each transcript is analysed separately (Cheng, Lo, Chan, Kwan, \& Woo, 2010) before looking for patterns across the transcripts and producing final super-ordinate themes, each of which contained a number of sub-themes. As part of a $\mathrm{PhD}$ project the lead researcher analysed all interviews before looking for overarching super-ordinate themes. The themes were refined multiple times in consultation with the project supervisors before the final list of super-ordinate themes were agreed. Furthermore, the study followed the four principles for assessing the quality of qualitative work as set out by Yardley (2000) - sensitivity to context, commitment and rigour, transparency and coherence and impact and importance. Themes were identified based on their frequency within the data set with those that occurred in over half being deemed super-ordinates themes. All identifiable information was removed from transcripts prior to analysis and pseudonyms were used for all participants.

\section{Ethics}

Ethical approval was obtained from Northumbria University research ethics committee in May 2011, and from the National Health Service (NHS) research ethics committee in August 2011.

\section{Findings}

Following the stages of analysis outlined above two super-ordinate themes emerged relating to the psychosocial and physical outcomes following treatment for cancer and how this impacted on their ability to view and make plans for the future: physical and psychological consequences of cancer; and adapting to life after treatment. Each of these themes contained a number of subthemes.

Physical and Psychological consequences of cancer 
Numerous physical and psychological symptoms relating to cancer and its treatment were reported by this group of participants. The experience of factors such as fear of recurrence, and functional impairment were all related to a disrupted view of the future.

\section{Fear of cancer recurrence}

The potential for cancer returning in the future was a worrying prospect for all participants and it emerged in all of the interviews to some extent. The uncertainty that participants felt about their future was a disruptive force in their lives and with implications for how they planned their futures. However, this disruption may only be temporary and can be caused by pending followup appointments, which soon ease if there is no indication of cancer returning. The repeated use of the term grandchildren in the quote below from Sarah illustrates the importance of spending time with her family since her diagnosis. Furthermore, there is a sense that booking trips away with family is almost a reward for her remaining cancer free.

"I've got me Grandchildren and funny enough since this happened I've started to take me grandchildren away for, on, national holidays for weekends and we enjoy ourselves. Just to Blackpool, Scarborough. Take the two grandchildren away and erm, of course we booked up to go and see the Harry Potter eh studios in April coming... Me daughter is going with me two grandchildren and erm I'm thinking I'll never get to see this, you know I'll never go, and then of course (all clear) so now I feel, I'm looking forward to going to see that with them." - Interview 1 - Sarah 
"I said if it's alright after me [my] colonoscopy then I'll book another trip away for us [grandchildren]." Interview 2 - Sarah

Fear of cancer recurrence can be heightened by an over vigilance to symptoms in the body which may indicate that cancer has come back. The quotes below highlight that experience is temporal and can emerge in participants who had never previously expressed concerns. However, the quotes that follow reinforce the importance of having symptoms checked, which can reduce feelings of fear of recurrence. Having said that, by waiting three months to have his symptoms checked by a health professional, Geoff has prolonged his experience of fear of recurrence. This indicates that he was afraid that his suspicions would be confirmed by a health professional and he would have to face cancer again.

"I don't sort of really think (because) I've had (it) that it can come back at any time so I best not make long term plans. So working on that basis, I don't let it affect us, really. If it comes back then... that changes everything but I don't live me life thinking it will come back so I'll not, not make plans." Interview 1 - Geoff

"I had some symptoms, similar to the symptoms I originally had erm and these lasted for bout three months erm, without wanting to go into too much detail, what the symptoms was, I was concerned, but not massively concerned, because it wasn't blood. So but I had some symptoms, it lasted about three months which did cause concern and obviously when erm... when you've had something like I've had... when there's something not right you immediately think 'oh it's back' and it, it, it's difficult not to think that way. Erm and I got in touch with $(C N S) \ldots$ it was agreed the to do another colonoscopy which I had mid August which proved fine, there was no erm 
major issues. Erm the only downside I have of that is, the symptoms still where there, for all it meant I didn't have bowel cancer and obviously something was not right." Interview $2-$ Geoff

\section{Functional Impairment}

Many of the participants in this study discussed experiencing functional impairment after being treated for cancer. This could be in the form of fatigue, pain, or the need to wear a colostomy bag after being fitted with a stoma. The impact of functional impairment has the possibility to cause disruptions to patients' views of, and ability to plan for, the future. As part of his treatment for colorectal cancer, John has a permanent stoma, which had caused him to question his career as a catering manager as it left him feeling uncomfortable at the thought of potentially working with food whilst wearing a colostomy bag. However, over time John has learned to adapt to his situation and by the second interview was no longer looking for an alternative career. This suggests that by trying out irrigation made him feel more comfortable working in the catering industry as he could take control of his condition and empty his bowels on his own terms. This would reduce the risk that he would have a bowel movement at work, something which may have been causing his uncertainty over continuing with his career.

"I was thinking about a career change or a step in a different direction anyway with it being like what I've got now, like the colostomy and everything but there, this has probably pushed us in the other direction to look for something different... I've been thinking for a while, as I say it's quite a heavy job to start with and it's, I mean I've got plenty work, it's a decent job I like me job and everything but it's just I've been 
thinking about it for a while and like I say it's been quiet for a long time, I've been expecting redundancy for quite some time." - Interview 1 - John.

"Fine, I mean since the irrigation, since I started doing the irrigation (I -so you decided...) and it's been absolutely brilliant, to be honest if I had of had the bag like I would have found, that was one of me big concerns, if the irrigation hadn't of worked or anything like that I think I would have found it hard going back into catering. Just basically if you are wearing a bag when you are serving customers I just wouldn't of felt right serving customers food, if I could feel me bag filling up" Interview $2-J o h n$.

However, if patients are unable to adapt to functional impairment then they may continue to experience a disruption to their views of the future for a long period of time. This can be distressing as activities that many would take for granted such as going to the gym become another reminder of the disruption caused to a patient's life. The quotes below illustrate that this functional impairment has persisted long-term for Geoff and suggest that his lack of stamina is a permanent reminder of his cancer journey. By discussing that he never thinks he will regain the stamina this suggests that he has accepted that his life has changed and that he will not be as physically active as he previously was. This is confirmed in the second interview where he reiterates his lack of stamina, and he makes no mention of renewed attempts to regain this suggesting that he has not attempted going back to the gym since the initial attempt. 
"The one thing that I've noticed is, that I never got back was the stamina or strength that I had. I tried to go back to the gym about a year later and I never got it back again. I don't think I'll ever get back to the levels I was, stamina wise." Interview 1 Geoff.

"I was also a bit lethargic as well, feeling tired all of the time, physically, but I have been generally since I was ill anyway, I've never had the stamina that I've had." Interview $2-$ Geoff.

Functional impairment can also have an impact on participant's family lives as partners or spouses also have to make adjustments. For example, Lindsay was struggling to sleep in her bed following her treatment and in order to help with this, her husband bought her an electronic bed which she could adjust in order to get comfortable. However, this has meant that her husband moved into a different room, this highlights that for Lindsay bed time is a reminder of her condition as her and her husband no longer share a bed, or even the same room. However, by describing the situation as fantastic this illustrates that increased level of comfort has somewhat compensated for this change in their living arrangements..

“Well, I could... I could make the stairs but, I couldn't lie in me bed em I couldn't get comfortable with me spine and having to be propped up in bed so (husband) emptied the bedroom and as I say he moved into the other big room and he bought me an electric bed which has been fantastic em, it was (consultant) had ordered a bed to be 
taken up onto his ward for me knowing that I'd had the spinal problems." - Interview $1-$ Lindsay

Adapting to life after treatment

How a participant makes sense of, and copes with an illness can impact on how they adjust. The participants in this sample used a range of coping mechanisms to adjust to their lives after being diagnosed with colorectal cancer, ranging from positive, problem focused coping strategies, to negative strategies such as avoidance.

\section{Making Sense of Symptoms}

A common theme which emerged from this study was that participants failed to have symptoms checked by a doctor prior to their initial diagnosis, instead attributing them to a pre-existing medical condition. This method of coping persisted after treatment when the onset of symptoms which may have indicated recurrent cancer were dismissed. This avoidance can exacerbate fear of recurrence as not knowing what is causing the symptoms may lead to persistent thoughts that cancer has returned.

"I'd just been leaking blood em that went on for about three days and went away so I just put it down to haemorrhoids. About 10 days later a similar thing happened ... because I've got a family history of bowel cancer erm I arranged an appointment with the doctor." Interview 1 - Geoff 
"I had some symptoms, it lasted about three months which did cause concern and obviously when ... there's something not right you immediately think 'oh it's back'." Interview $2-$ Geoff

\section{Lifestyle Adjustments}

In order to cope with living with and beyond cancer participants discussed a number of adjustments they had made to their lives. A failure to adapt to life following cancer may lead to future disorientation and the avoidance of situations which remind them of the future they had lost. For example, John had quite an active social life prior to his illness but was struggling with pain following his operation, and was struggling to adapt to wearing a colostomy bag. Prior to the first interview he had just been out socially for the first time following his operation but only managed to stay out for a few hours. However, as he progressed through his cancer journey and learned how to adapt, he had developed new coping mechanisms and is starting to engage in more social activities. As long as he knew in advance when he was going out and could time his irrigation then he was happy going out and socialising with friends and family. As outlined above this suggests that John has taken control of his condition, and by irrigating his stoma he is able to plan his social activities to ensure that his condition has a minimal impact on his life.

“Well, I mean I've, I went out for the first time on Saturday night gone, that was just like a family do eh it was me sisters, eh me wife's sisters 70th birthday and that was just like a few hours in the pub and a bit of a get together sort of thing eh I haven't been out that much since then but like since the operation obviously I've been like in too much pain and been taking painkillers" Interview 1 - John 
"Yeah we go out regularly, we go out for meals couple of times a week and what have you down the local pub I've been out with friends out in the town and what have you, it's just no problem at all now, just go out when I feel like it basically, just nothing stopping, I just tend to do the irrigation, so it like coincides with us going out" Interview 2 - John

However, not everyone felt that they needed to make adjustments to their life in order to adapt to living with cancer as a chronic illness. For some their cancer journey had given them a chance to reflect on what is important in life and they have chosen to spend more time with family. The below quote illustrates that prior to his diagnosis Paul prioritised socialising with friends and spent a lot of time drinking alcohol. However, following his treatment and a chance to reflect on what is important in life he has chosen to spend more time with his partner, whilst still maintaining some element of a social life.

"I mean I don't drink as much now as I used to cause I used to be a well seven days a week... but only two or three pints but now I'm only going once a week. I mean I like going out for meals, me and the wife we like Italians, Indians somewhere different... looking on life different to what I did then." Interview 1 -Paul.

\section{Functional Social Support}

Family support seemed to be an important factor in adjusting to living with colorectal cancer as a chronic illness. Whist participants felt that they received great levels of support from their family they did discuss that close family members themselves perhaps struggled to deal with their 
illness. For example, whilst overall across both interviews Geoff felt that his wife was there to support him, describing her as 'Florence Nightingale' he did feel that she was struggling to cope, and was perhaps in denial about what had happened. This denial may have contributed to tension between them which led to a series of arguments.

"Me wife actually was quite strange erm it was almost as if it never knocked her out of her stride em as if nothing had happened there was quite a few arguments went on at the time however, after the op... during the operation like the day before and then during the operation and then after the operation she was like Florence Nightingale she was amazing so I got the impression that she struggled to cope with it" Interview $1-$ Geoff

"She was marvellous with it and she has gotten over it, I don't think she has ever really come round to what it was and what you go through erm she does, it hasn't really affected her" Interview 2 - Geoff

John had a similar experience where his wife was the main source of support through his cancer journey, however he was also overwhelmed from the support he received from his wider family. Whilst initially John appeared reluctant to burden his parents, and only look to his wife for support, as he continued on his cancer journey he appeared to open himself up to drawing on his parents for support. As discussed previously, John may have been initially struggling to cope with his illness but following his decision to take control of his condition he is now perhaps more 
comfortable talking about his condition with other people, and thus opening up his support network.

"Yeah I mean my wife's brilliant she's been me nurse, me best friend and everything basically over the last few months, erm me family's always been there, like I say I've got me mam and dad, I've got me two sisters and I haven't got a massive bunch of friends but the ones who I have got like they're really good friends and really close friends, and I've had loads of support off them... didn't want to upset my mam and dad too much cause they've got enough on their plate being 70 year old and looking after me sister." Interview $1-J o h n$.

"I'm open as anything with them, I just they know everything I have been through, they know I am fine, if I had any problem with them I would tell them straight away now. I feel more confident about it, in meself and stuff like that as well, I mean if I'm feeling down or bad about anything then I think that they need to know about it" Interview $2-$ John.

\section{Discussion}

To date few studies have explored the experience of future disorientation in patients living with and beyond cancer, and those which have, have tended to focus on women treated for gynaecological cancers. This study has expanded our knowledge of future disorientation by exploring the phenomenon in men and women living with colorectal cancer, and by looking at experiences over time. 
The present results mirror previous studies which have shown that the psychosocial and physical complications associated with living with colorectal cancer as a chronic illness can have serious implications for how well patients adjust (Appleton et al, 2013; Brown et al, 2016; Rodriguez et al, 2015). Furthermore, studies have shown that patients living with and beyond cancer are particularly susceptible to fear of recurrence, one of the most common psychosocial impacts of a cancer diagnosis, being reported in up to $49 \%$ of patients living with and beyond cancer (Maheu et al., 2016). Like previous studies, fear of recurrence was a common complaint in this study and was discussed to some extent in all interviews.

Previous research has highlighted that functional impairment can have implications when it comes to returning to employment following treatment for cancer with those living with and beyond cancer facing increased risk of unemployment, early retirement and are less likely to be re-employed (Kiserud et al., 2014). However, the results of this study highlighted that if a patient is able to adapt to their functional impairment then they can overcome their future disorientation and return to their previous employment, although it must be acknowledged that only one of the two participants who was working at the time of the study reported this.

Evidence suggests that how an individual makes sense of, and copes with, an illness can impact on how well they adjust to their illness (Appleton et al, 2013; Bloom \& Spiegel, 1984; CoussonGelie, Bruchon-Schweitzer, Dilhyudy, \& Jutand, 2007; Llewellyn, Weinman, McGurk, \& Humphris, 2008). The results of the present study seem to support this; participants who described finding ways of adjusting to living with colorectal cancer as a chronic illness also expressed experiencing future disorientation to a lesser extent than those who did not.

By interviewing patients at two time points we have demonstrated that the future disorientation which arises out of the uncertainty caused by living with colorectal cancer as a chronic illness is 
not omnipresent but dependent on a number of factors such as how well patients adapt to functional impairment, and fear of recurrence. Furthermore, future disorientation may be linked to the experience fear of cancer recurrence and more prevalent at certain times such as before follow-up appointments or when they may have experienced potential symptoms of recurrence. However, this uncertainty over the future may begin to reduce as participants begin to adjust to living with cancer as a chronic illness.

Implications for practice

What is clear from this study is that patient's adjustment to living with and beyond cancer as a chronic illness can vary over time. Certain events such as the onset of new symptoms, or the anniversary of a diagnosis can all impact on levels of adjustment and subsequently on how patients plan for their futures. Clinicians should be aware that patients may need additional support at key points along their cancer journey and that the provision of timely support may help patients make both short and long-term plans for their future.

\section{Limitations of this study}

Whilst this study has provided an overview of the experience of future disorientation in men and women living with colorectal cancer as a chronic illness over time there is still much work to be done if we are to fully understand the psychosocial impact of living with and beyond cancer. Gatekeepers were used to recruit participants and they did not record how many people they approached therefore we are unaware of what the uptake rate was for this study. While this qualitative study has outlined some of the causes of future disorientation, as well as factors which may protect against future disorientation, there is a need for a larger scale study involving patients diagnosed with other forms of cancer to build up a fuller picture of this phenomenon. 
There were also some limitations with the data collection, whilst this study explored the impact of living with and beyond colorectal cancer as a chronic illness, participant understandings of the nature and impact of chronicity were not explored. Future research in this area is needed to understand the long-terms consequences of living with and beyond cancer in this under researched population. 


\section{References}

Appleton, L., Goodlad, S., Irvine, F., Poole, H., \& Wall, C. (2013). Patients' experiences of living beyond colorectal cancer: a qualitative study. European Journal of Oncology Nursing, 17(5), 610-617.

Balfe, M., Maguire, R., Hanly, P., Butow, P., O'Sullivan, E., Timmons, A., et al. (2016). Distress in long- term head and neck cancer carers: a qualitative study of carers' perspectives. Journal of Clinical Nursing, 25, 2317-2327.

Bell, S. L., Tyrrell, J., \& Phoenix, C. (2016). Ménière's disease and biographical disruption: Where family transitions collide. Social Science \& Medicine, 166, 177-185.

Bloom, J. R., \& Spiegel, D. (1984). The relationship of two dimensions of social support to the psychological well-being and social functioning of women with advanced breast cancer. Social Science \& Medicine, 19(8), 831-837.

Breaden, K. (1997). Cancer and beyond: the question of survivorship. Journal of Advanced Nursing, 26, 978-984.

Brown, S., Greenfield, D., \& Thompson, J. (2016). Knowledge and awareness of long-term and late treatment consequences amongst colorectal cancer survivors: A qualitative study. European Journal of Oncology Nursing, 20, 191-198.

Bury, M. (1982). Chronic illness as biographical disruption. Sociology of Health and Illness, 4, $167-182$.

Cancer Research UK. (2018a). Worldwide cancer incidence statistics. Retrieved $3^{\text {rd }}$ March 2018 http://www.cancerresearchuk.org/health-professional/cancer-statistics/worldwide$\underline{\text { cancer/incidence\#heading-Zero }}$ 
Cancer Research UK. (2018b). Cancer Statistics for the UK. Retrieved $3^{\text {rd }}$ March 2018 http://www.cancerresearchuk.org/health-professional/cancer-statistics

Charmaz, K. (1983). Loss of self: a fundamental form of suffering in the chronically ill. Sociology of health \& illness, 5(2), 168-195.

Cheng, J. O. Y., Lo, R. S. K., Chan, F. M. Y., Kwan, B. H. F., \& Woo, J. (2010). An exploration of anticipatory grief in advanced cancer patients. Psycho-oncology, 19, 693-700.

Costanzo, E. S., Lutgendorf, S. K., Mattes, M. L., Trehan, S., Robinson, C. B., Tewfik, F., et al. (2007). Adjusting to life after treatment: distress and quality of life following treatment for breast cancer. British Journal of Cancer, 97(12), 1625-1631.

Courneya, K. S., Mackey, J. R., \& Jones, L. W. (2000). Coping with cancer: can exercise help? The Physician and Sportsmedicine, 28(5), 49-73.

Cousson-Gelie, F., Bruchon-Schweitzer, M., Dilhyudy, J. M., \& Jutand, M. A. (2007). Do Anxiety, Body Image, Social Support and Coping Strategies Predict Survival in Breast Cancer? A Ten-Year Follow-Up Study. Psychosomatics, 48(3), 211-216.

Drageset, S., Lindstrøm, T. C., \& Underlid, K. (2016). "I just have to move on": Women's coping experiences and reflections following their first year after primary breast cancer surgery. European Journal of Oncology Nursing, 21, 205-211.

Gahzzali, N., Cadwallader, E., Humphris, G., Ozakinici, G., \& Roger, S. N. (2012). Fear of recurrence among head and neck cancer survivors: longitudinal trends. Psycho-oncology, 22(4), 807-813.

Handschel, J., Naujoks, C., Kubler, N. R., \& Kruskemper, G. (2012). Fear of recurrence significantly influences quality of lfe in oral cancer patients. Oral Oncology, 48(12), 1276-1280. Herschbach, P., \& Dinkel, A. (Eds.). (2014). Fear of Progression. Berlin: Springer. 
Ho, M. Y., McBride, M. L., Gotay, C., Grunfeld, E., Earle, C. C., Relova, S., ... \& Cheung, W. Y. (2016). A qualitative focus group study to identify the needs of survivors of stage II and III colorectal cancer. Psycho- Oncology, 25(12), 1470-1476.

Horikoshi, M., \& Futawatari, T. (2017). The Process of Accepting Functional Impairments among Male Rectal Cancer Patients after Surgery. 北関東医学 The Kitakanto Medical Journal, $67(1), 1-11$.

Independent Cancer Taskforce. (2015). Achieving world-class cancer outcomes: A strategy for England 2015. Retrieved $7^{\text {th }}$ January 2018 https://www.england.nhs.uk/publication/achievingworld-class-cancer-outcomes/

Jiwa, M., Saunders, C. M., Thompson, S. C., Rosenwax, L. K., Sargant, S., Khong, E. L., et al. (2008). Timely cancer diagnosis and management as a chronic condition: opportunities for primary care. The Medical Journal of Australia, 189(2), 78-82.

Kiserud, C. E., Dahl, A. V., Loge, J. H., \& Frossa, S. P. (Eds.). (2014). Cancer survivorship in adults. Berlin: Springer.

Lebel, S., Ozakinci, G., Humphris, G., Mutsaers, B., Thewes, B., Prins, J., et al. (2016). From normal response to clinical problem: definition and clinical features of fear of cancer recurrence. Supportive Care in Cancer, 24(8), 3265-3268.

Llewellyn, C. D., Weinman, J., McGurk, M., \& Humphris, G. (2008). Can we predict which head and neck cancer survivors develop fears of recurrence? Journal of Psychosomatic Research, 65(6), 525-532.

Maguire, R., Stoddart, K., Flowers, P., \& Larkin, M. (2014). An Interpretative Phenomenological Analysis of the lived experience of multiple concurrent symptoms in patients with lung cancer: A 
contribution to the study of symptom clusters. European Journal of Oncology Nursing, 18(3), 310-315.

Maheu, C., Lebel, S., Courbasson, C., Lefebvre, M., Singh, M., Bernstein, L. J., et al. (2016). Protocol of a randomized controlled trial of the fear of recurrence therapy (FORT) intervention for women with breast cancer or gynaecological cancer. BMC Cancer, 16(1), 1.

Maughan, K., \& Clarke, C. (2001). The effect of a clinical nurse specialist in gynaecological oncology on quality of life and sexuality. Journal of Clinical Nursing, 10(2), 221-229.

Office for National Statistics. (2017a). Cancer registration statistics, England: First release, 2015.

Office for National Statistics. (2017b). Cancer Survival in England: Patients diagnosed between 2010 and 2014 and followed up to 2015.

Pélissier, C., Fontana, L., \& Chauvin, E. (2014). Factors influencing return to work after illness in France. Occupational Medicine, 64, 56-63.

Roberts, K., \& Clarke, C. (2009). Future disorientation following gynaecological cancer: Women's conceptualisation of risk after a life threatening illness. Health, risk \& society, 11(4), 353-366.

Rodriguez, J. L., Hawkins, N. A., Berkowitz, Z., \& Li, C. (2015). Factors associated with healthrelated quality of life among colorectal cancer survivors. American journal of preventive medicine, 49(6), S518-S527.

Sahay, T. B., Gray, R. E., \& Fitch, M. (2000). A qualitative study of patient perspectives on colorectal cancer. Cancer practice, 8(1), 38-44.

Smith, J. A., Flowers, P., \& and Larkin, M. (2009). Interpretative Phenomenological Analysis: Theory, Method, and Research. London: SAGE Publication. 
Trusson, D., Pilnick, A., \& Roy, S. (2016). A new normal?: Women's experiences of biographical disruption and liminality following treatment for early stage breast cancer. Social Science \& Medicine, 151, 121-129.

World Health Organization. (2018). Cancer: Factsheet. Retrieved $3^{\text {rd }}$ March 2018 http://www.who.int/mediacentre/factsheets/fs297/en/.

Yardley, L. (2000). Dilemmas in qualitative health research. Psychology and health, 15(2), 215228. 